\title{
Design and implementation of a smart solid waste collection system
}

\author{
K. Cavdar $^{1} \cdot$ M. Koroglu ${ }^{2}$ B. Akyildiz ${ }^{2}$
}

Received: 12 July 2015/Revised: 17 March 2016/Accepted: 12 April 2016/Published online: 25 April 2016

(C) Islamic Azad University (IAU) 2016

\begin{abstract}
Solid waste collection systems are very important in today's urban environment. The last three decades witnessed the development in urban areas over rural ones in a process called urbanization. Growth of urbanization is much more in developing countries than in the developed countries to the extent that it became a trend characterizing several developed and even least developed countries. Unfortunately, it has been observed that the systems currently used in modern cities do not provide a service of sufficient efficiency and quality, despite their high running costs. As an alternative, a smart solid waste collection system with all subcomponents was developed and applied in a small city in Turkey. In addition to the conventional waste collection systems, this system included smart features and optimization algorithms for route planning. The study presents the design philosophy, feasibility and pilot implementation of a smart solid waste collection system which can be operated with high efficiency at low cost.
\end{abstract}

Keywords Design · Expert system · Productivity - Solid waste $\cdot$ System design

K. Cavdar

cavdar@uludag.edu.tr

1 Faculty of Engineering, Uludag University, Gorukle Kampusu, 16059 Bursa, Turkey

2 AKA Otomotiv San. ve Tic. A.S., Ornekkoy Yolu, 1. Km, 16800 Bursa, Turkey

\section{Introduction}

As civilization progressed, people began to seek the comfort and convenience of life in the cities. Nowadays, the rate of urbanization is cited as one of the indicators of a county's level of development. However, urbanization and the fact that more people are living together have also brought about problems in areas such as traffic, health and security. One of the biggest concerns in cities, and one which needs careful consideration, is the installation and operation of a solid waste collection system. It has been generally observed that in modern cities, either this process is performed poorly or the operational efficiency of the system in use is inadequate. The inevitable result is that city residents start to complain about the service provided and local civic authorities are dissatisfied with the costs involved.

According to Encyclopedia Britannica, solid waste management- the collecting, treating and disposing of solid material that is discarded because it has served its purpose-is no longer useful. Improper disposal of municipal solid waste can create unsanitary conditions, and these conditions in turn can lead to pollution of the environment and to outbreaks of vector-borne diseasethat is, diseases spread by rodents and insects. The tasks of solid waste management present complex technical challenges. They also pose a wide variety of administrative, economic and social problems that must be managed and solved.

EEA Report No 2/2013 gives a review of achievements in 32 European countries for municipal waste. According to report, countries use varying definitions of municipal solid waste and such differences create uncertainties when assessing waste management, especially when comparing national performance. 
New developments in solid waste collection systems and the existing studies on this subject have been summarized below.

The study carried out by Vicentini et al. (2009) illustrates the structure of a waste collection system which uses containers installed with waste-level detection sensors. The case studies of Zaman (2013) and Son (2014) describe optimized waste collection processes using mathematical programming techniques carried out in Sweden, Buenos Aires and Danang cities, respectively. In the second study, which used the classic shortest path algorithm, the saving that could be made in one small district of the city was calculated to be USD 200,000 per year. A similar study carried out in Greece was reported by Hadjibiros et al. (2011).

A variety of other methods have been used to calculate the shortest path in the collection of waste (Abeliotis et al. 2009; Ezebilo and Animasaun 2011). Ismail and Loh (2009) carried out their optimization process using an ant colony approach. Their theoretical study was conducted using transfers between 12 and 48 points, and they discussed the possible application of this methodology to waste collection problems. A similar approach was also suggested by Karadimas et al. (2007).

In Sweden, Johansson (2006) presented his optimization study for a solid waste collection process using a container system equipped with 3300 sensors and wireless communication equipment. In order to decide the optimal route in the waste collection process, real-time data obtained from the containers were used. At the end of the study, it was determined that the cost of collecting solid waste had been reduced by 10 to $20 \%$.

Faccio et al. (2011) applied multi-objective models using real-time data to the waste collection process. The study was carried out in an Italian town with a population of approximately 100,000.

A study using a genetic algorithm to determine the optimum route was presented by Viotti et al. (2003). This software algorithm could greatly increase the efficiency of the solid waste collection systems.

Nuortio et al. (2006) developed a system for the optimization of the waste collection process in a project in western Finland. In this operating zone, there were in total approximately 30,000 waste bins and explained the concept model of this system.

Arebey et al. (2010) presented the design model of a waste collection system which used RFID (Radio Frequency Identification), a GPS (Global Positioning System) and cameras. The system also used Digital Image Processing to determine how full the containers were.

Guerrero et al. (2013) reviewed some articles on the applications of solid waste management for developing countries. A comprehensive list of stakeholders that are relevant in the waste management systems presented and obtained quantitative information about the systems. This information provided is very useful when planning, changing or implementing waste management systems in cities.

Kop (2007) examined the existing waste management legislation and processes in Turkey along with global examples of these processes and discussed Turkey's world position in this sector. In order to compare waste collection systems as a part of the solid waste collection process, data on existing and anticipated collection systems were assembled from various private companies and public authorities. The latter included municipalities as well as the Ministry of Environment and Forestry. In line with these data, the most appropriate waste collection system was chosen. Chen (2010) analyzed the spatial inequality in municipal solid waste disposal across regions in the developing countries and developed a multiple regression model to quantify the relationship between several factors (such as population density, old age composition, unemployment rate, the education level) and municipal solid waste disposed (as the dependent variable).

Based on a projection carried out for the city of Istanbul using data for 2010, it was calculated that an annual saving of USD 80 million could be achieved by overhauling and increasing the efficiency of the waste collection system. This would then amount to an annual saving of USD 400 million for the whole of Turkey (eBelediye 2014).

This project was performed in Bursa-Kestel city in Turkey. A smart solid waste collection system with all subcomponents was developed as an alternative system for all modern cities. This system included some smart features and an optimization algorithm for route planning unlike the conventional waste collection systems. After 2 years of preparatory phase, implementation was carried out in 2014. In 2015, the design requirements were optimized and began the applications to other residential areas. The design philosophy, feasibility and pilot implementation of the smart solid waste collection system are presented in next sections.

\section{Materials and methods}

After an examination of the literature and completion of detailed investigations and communications with municipalities in Turkey, it was decided that a new smart solid waste collection system (SSWCS) could be developed which would work more efficiently than the one presently being used. The projected benefits of the development of this system are listed below: 
- The levels of container fullness could be tracked from one central location (via web portal).

- Daily and weekly work-planning reports could be obtained from the system.

- Using GSM/GPRS, optimal routes could be determined, thus saving time and energy/fuel.

- Reporting could be tailored to the requirements, for example, monthly volume of waste according to districts, etc.

- Instead of eight conventional 400-1 containers, one underground waste container could be used.

- Instead of four conventional waste collection vehicles, only one smart waste collection vehicle would be needed.

- The decreased number of collection vehicles in the system would result in savings on repairs, maintenance and time.

- In the new system, there would be no need for the two operators working from the back of the vehicle, as in the conventional system.

- The system would fully comply with the Worker Health and Occupational Safety rules.

- Fatal accidents involving operators would be prevented.

- Cities would have a modern system which blends in aesthetically.

- The operating life of the system would be increased to 10 years.

- Waste collection would be more ergonomic and quicker.

- Traffic flow would not be disrupted.

- Noise and visual pollution would be removed from cities.

\section{Implementation of the SSWCS to a particular residential area}

For implementation, part of a residential area consisting of six districts was selected where 70-75 tons of waste is normally collected per day. The amount of waste collected in these six districts constitutes $80 \%$ of that of the residential area. Waste trucks are forced to enter the streets and roads repeatedly in an unplanned way because of the insufficient number of roads in the collection area, the inadequate capacity of the containers and because residents do not put out their waste at the designated time. This lack of planning generally causes environmental problems such as noise and unpleasant odors.

Table 1 shows a sample feasibility survey carried out for a small residential area. When a conventional waste collection system was used, staff costs (in Turkish Lira) for the area were TL 647,964 , whereas the cost was only TL 45,576 when using the smart waste collection system, due to the decrease in the number staff and vehicles. The annual cost of fuel and depreciation would be reduced from TL 1,537,200 to TL 629,280. A further saving of TL 238,750 could also be made by converting existing waste containers to be compatible with the smart waste collection system.

\section{Results and discussion}

The development of the system and the implementation as a pilot application were carried out. A diagram showing the logical principles of the SSWCS is shown in Fig. 1. The system consists of three main parts:

1. Container (underground and aboveground containers)

2. Vehicle (robotic waste collection vehicles)

3. Portal (starting point for reaching the user interface)

\section{Containers (underground and aboveground)}

There are two types of containers in the system: underground containers and aboveground containers. The underground containers are manufactured with capacities of 3.5 and $5 \mathrm{~m}^{3}$, weight 750 and $980 \mathrm{~kg}$, respectively, and are made of approximately 30 different standard materials and 150 different components. The aboveground containers are manufactured with the capacity of $3.4 \mathrm{~m}^{3}$, weigh approximate $45 \mathrm{~kg}$ and are made of 150 different components (Fig. 2).

The communication system placed in the container (Fig. 3) consists of an ultrasonic sensor, a SIM card (M2M), two lithium polymer batteries (5000 mAh), a main circuit board, an antenna and a system mounting protection box (IP67). The communication system operates in the following way: The amount of waste collected in the containers is measured by an ultrasonic sensor (a); the measured value is transferred to a specially designed circuit main board (b); and then, the value is sent to an "http" address using the SIM card (c) installed on the circuit main board; an antenna (d) supports the satellite connection of the SIM card installed in the communication system; and two $5000 \mathrm{mAh}$ lithium polymer batteries (e) meet the power needs of the system; finally, in order to protect the communication system against external impacts, it is contained in an IP67 class installation box (f).

After the appropriate amount of waste is transferred to the container, a digital identity is assigned to it. This digital identity is assigned using the RFID (radio-frequency 
Table 1 Sample feasibility study conducted for a small district (TL: Turkish Lira)

Monthly income (TL) Daily income (TL) Nr of workers $\quad$ Daily costs (TL) Monthly costs (TL)

Existing system

Municipality cost for one driver 1900

Municipality cost for one employee 1750

$\begin{array}{llrl}63.33 & 10 & 633.30 & 18,999.00 \\ 58.33 & 20 & 1166.60 & 34,998.00 \\ \text { Totally } & 30 & 1799.90 & 53,997.00\end{array}$

Waste collection system with underground containers ( 2 trucks and 2 drivers)

Municipality cost for one driver

1900

63.33

2

126.60

3798.00

Totally

2

126.60

3798.00

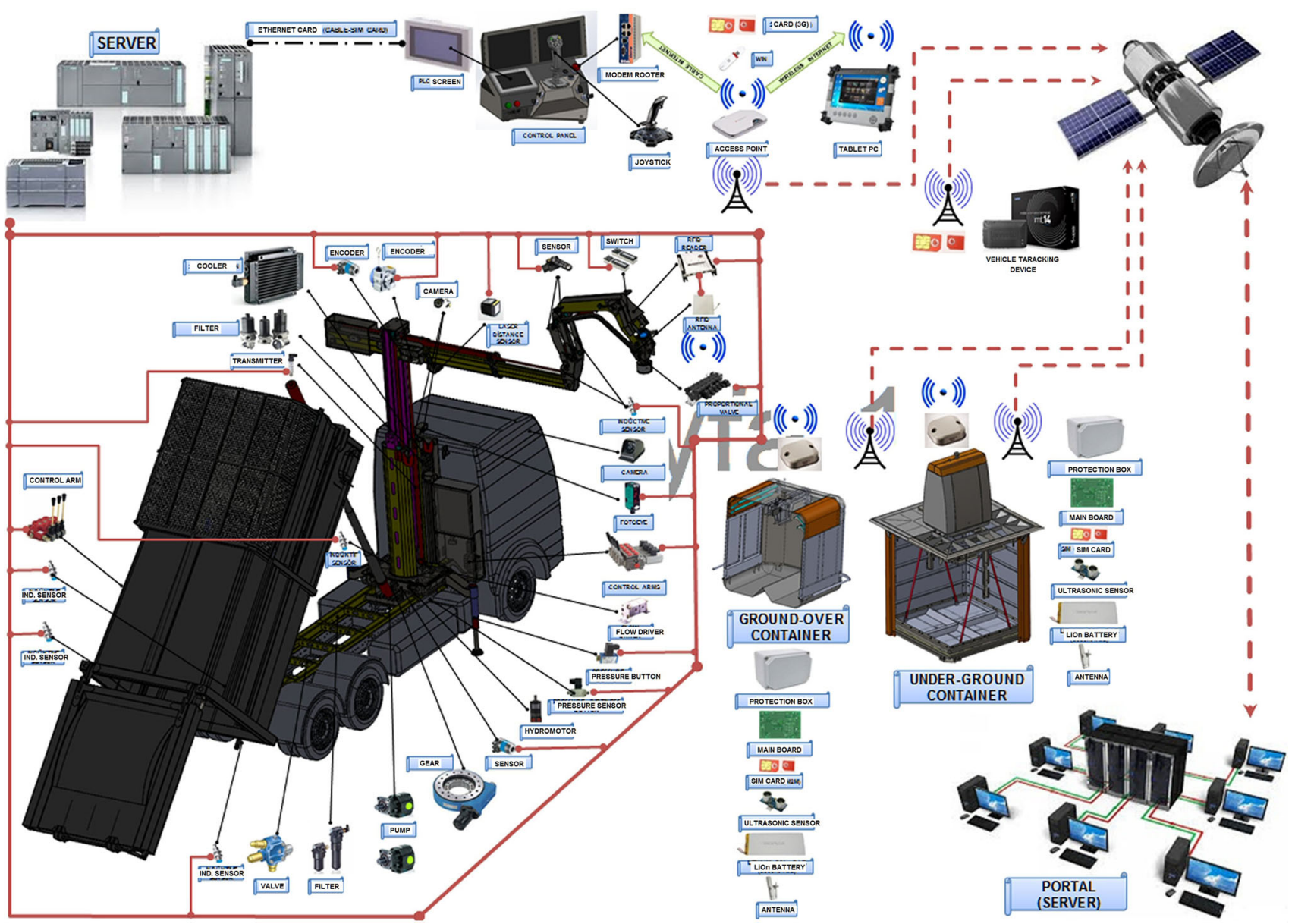

Fig. 1 Principle scheme of the smart solid waste collection system

identification) system and the RFID tag on the top of the container (e.g., yak000001, yük000001). Using this digital identity, a smart system is set up to determine which containers are full, which ones have been emptied, how many kilograms of waste are in the containers and how much waste is being generated in different districts. In addition, the system can make decisions about the adequacy of the number of containers in those districts.

\section{Vehicles (robotic waste collection vehicles)}

The vehicles are constructed of 300 different standard materials and 550 different components (Fig. 4). The weight of the robotic waste collection vehicle is approximately 17 tons. The system is activated from the vehicle. Two hydraulic gears connected to the vehicle by an intermediate transmission box convert the kinetic energy 
Fig. 2 Types of container in the system

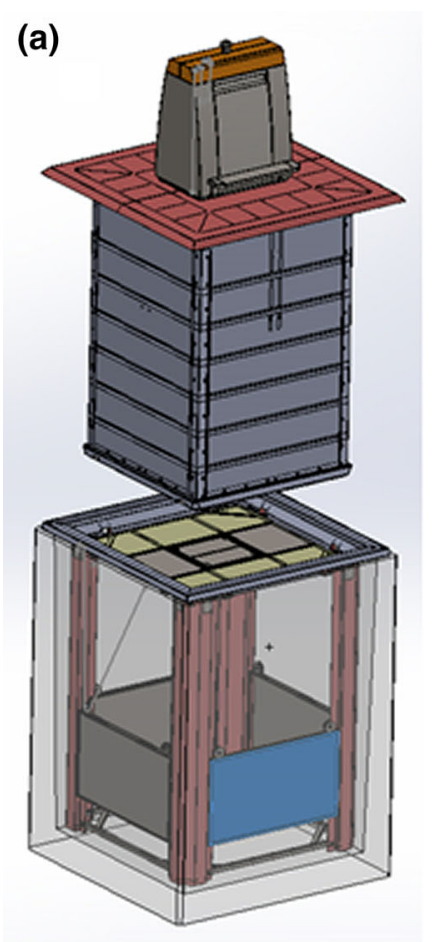

(b)

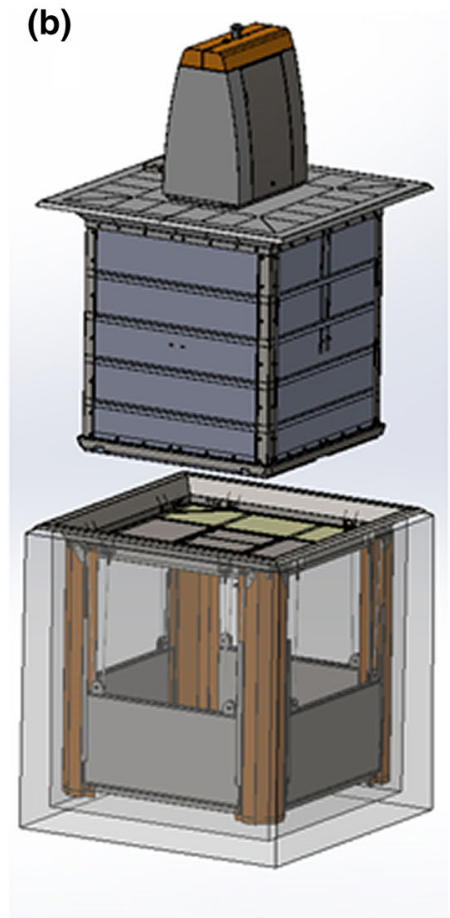

(c)

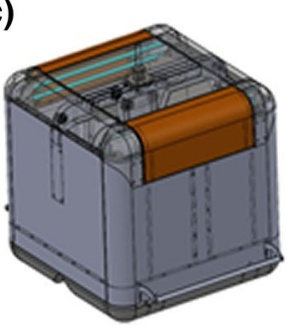

acquired from the pump transmission box into hydrostatic energy that operates the system using hydraulic actuators. An automation system has been designed to control the movement of the system. Because of the integrated operation of the hydraulic valves (proportional, solenoid) and the automation system software, the desired movements can be made with a sensitivity of $0.1 \%$.

When the driver maneuvers the vehicle to retrieve a waste container, the container is aligned using the cameras on a horizontal boom linked to a $10^{\prime \prime}$ screen installed in the cockpit. The driver presses the clutch to take the vehicle out of gear and after disengaging the clutch, the parking brake is engaged. Engaging the clutch again, button $\mathrm{Nr} 1$ is pressed, the PTO (power take off) is activated and oil is transferred from the pumps into the system. Button $\mathrm{Nr} 2$ on the joystick is pressed, and, according to where the joystick is held, the forward drive system starts to move on automatic pilot, the feet located on the right and left sides of the vehicle are used to balance it, and the top waste discharge cover is opened. The horizontal booms move forward, and, when the information received from the laser distance sensors located on the horizontal booms is read by the encoder and angle sensors, the retainer head-gripping jaw moves forward toward the nearest area of the container grip point. In order to make the process of taking hold of the container grip point easier, button $\mathrm{Nr} 2$ can be pressed to control left-right and buttons $\mathrm{Nr} 2$ and 3 together to control forward-backward motion. During the gripping process, the RFID antenna placed on the head, using RFID software, reads the numbers that are written on the RFID tag located on the container, via vertical and horizontal radio frequencies. These numbers reveal the digital identity of the container. The read values are registered on the PLC (Programmable Logic Controller) to be sent to the portal later. After the gripping process is completed, button $\mathrm{Nr} 2$ on the joystick is pressed again and the system continues its operation.

When the container is suspended, the weight of the container can be obtained using the transmitter located on the hydraulic line going to the vertical boom, and this is then matched with the container identity information which had previously been read from the RFID tag. In this way, the amount of waste in each container can be determined. The information obtained is then sent to the http address via API through the modem router ( $3 \mathrm{G}$ Internet) installed on the PLC system. When the container body gets to the upper waste discharge area, the pin pressing mechanism on the retainer head which opens the bottom covers of the container is activated and the waste inside the container is discharged into the frame. The waste is then compressed using the hydraulic compression mechanism in the frame. At the end of the waste discharge process, the system automatically replaces the container in its original position and moves into parking mode. After the system moves into parking mode, the clutch is pressed, the PTO is deactivated and the vehicle is ready to move again. Information about 
Fig. 3 Communication system placed in the container

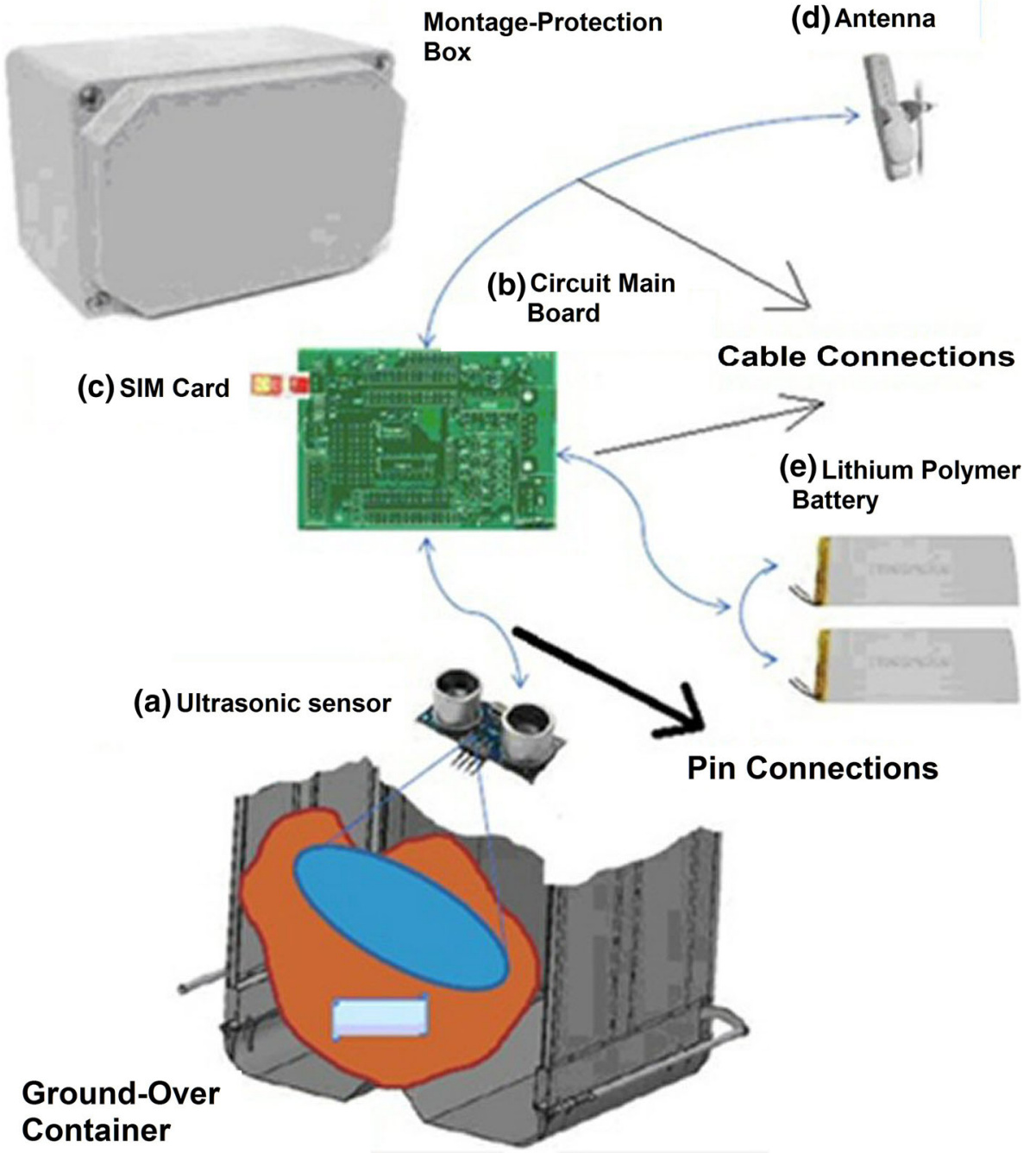

the robotic waste collection vehicle such as distance covered, location, speed, idle time, is provided using a special software package. This information is then printed out after a message has been sent to the main server via the M2M SIM card installed in the software package.

The cockpit of the robotic waste collection vehicle is equipped with a tablet PC (Fig. 5). The driver can connect to the Internet by means of this tablet (via $3 \mathrm{G}$ connection), and his routes and duties can be easily seen. Furthermore, it is possible to connect to the portal (user interface) to obtain real-time information on the containers, roads and so on.

\section{Portal (user interface)}

The third part of the system is the user interface (Fig. 6), also located in the cockpit, which facilitates the transfer of various kinds of information. This includes instantaneous information transfer between the system and user, retrospective reports, duty rosters, various comparisons, efficiency evaluations and vehicle routing. The information reaches the portal via satellite. The M2M SIM cards on the containers and vehicle transmit the information they receive from the sensors through messages via the Internet. The transferred information is shown to the users either after comparison with the desired values or in simple form using a specially designed software program. Notes on the working principles of the program are as follows:

- A description of the needs of the relevant municipality is put on the system by the portal administrator (i.e., company information, screen licenses, workers, user authority, users).

- The components to be used in waste collection and site information (vehicles, arrival and departure points, containers) are handled by the company that owns the system (AKA OTOMOTIV).

(a) Prior to creating identification for the vehicle, it is fitted with a tracking module. 


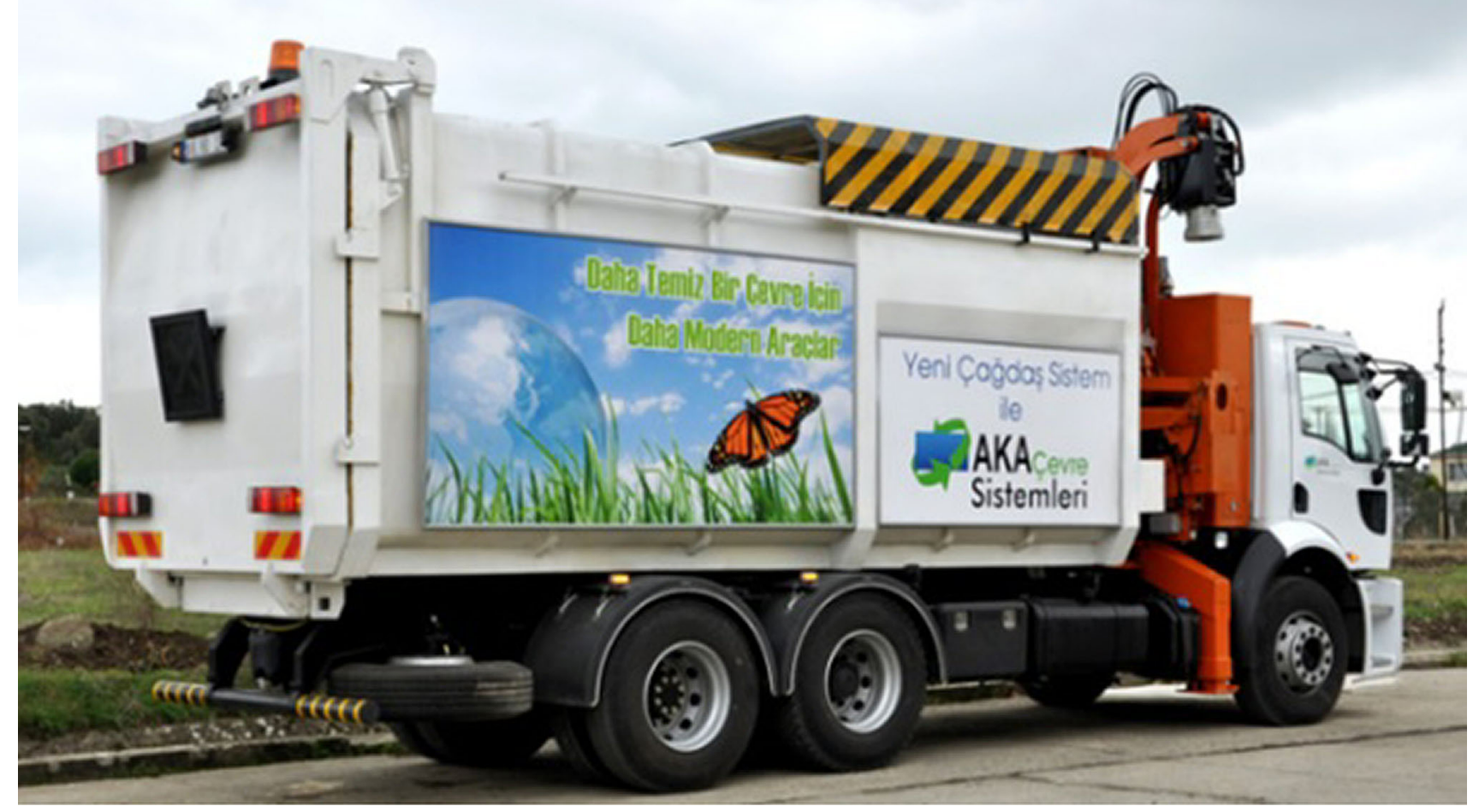

Fig. 4 Solid waste collection vehicle with robotic arm

Fig. 5 Cockpit design of the solid waste collection vehicle

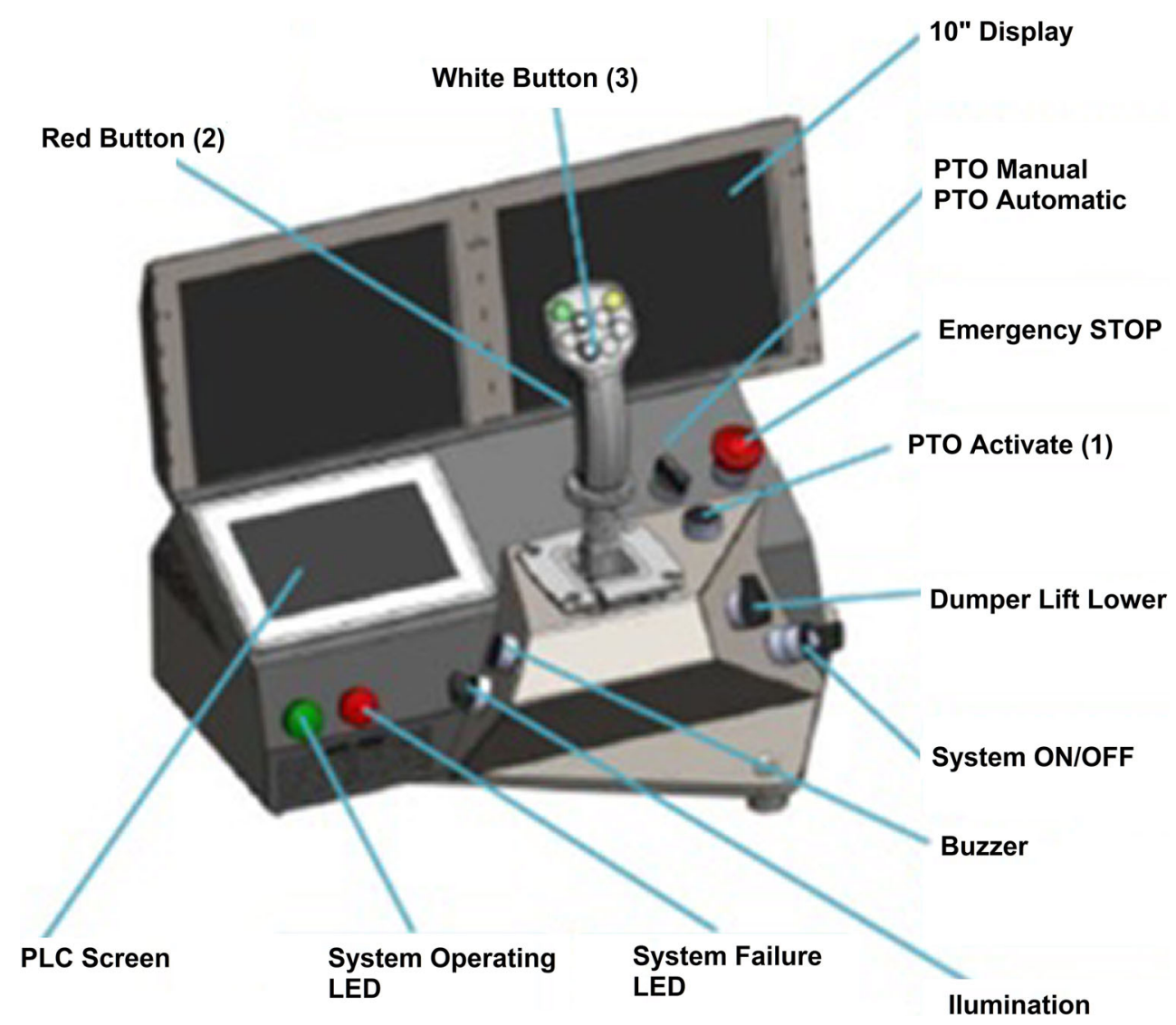




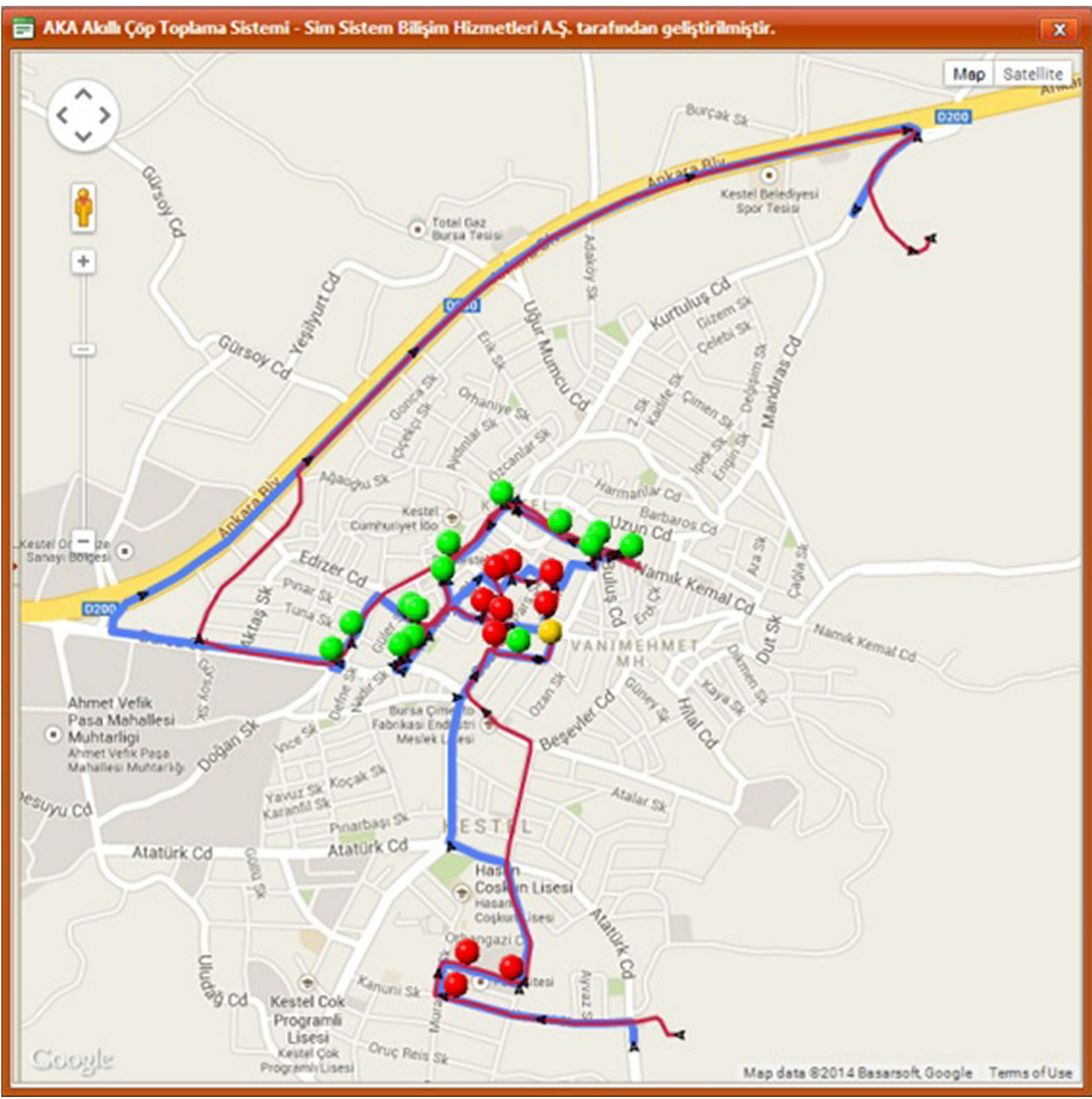

Fig. 6 User interface of the system

(b) Vehicle arrival and departure locations are determined.

(c) Before a container is put into the system, its coordinates are determined and a waste-level sensor and RFID tag are installed on it.

- Information is gathered using specially designed hardware and software installed in the vehicles and containers and is transmitted at regular intervals to the servers via a web service (the time intervals are determined by AKA OTOMOTIV).

(a) The module in the vehicle sends the information about the vehicle's location, speed, km counter, etc., to the system at regular intervals.

(b) The module in the container sends the information about the level of waste it contains to the system at regular intervals. 
(c) The container weighing module in the vehicle sends the weight of waste discharged into the system from each container.

- After this period is completed, the user can track the vehicles and containers with up-to-date information at desired time intervals and create work orders.

(a) The user (administrator) makes a plan on the screen of the containers to be collected and informs the driver by system SMS.

(b) When the driver actually starts the work order in question, he activates the work order from the portal.

(c) When the work order starts, vehicle information can be tracked at time intervals defined on the tracking screen.

(d) If the driver finishes the work order, he also completes the work order on the portal.

(e) The user (administrator) can report and analyze the completed work orders.

\section{Conclusion}

In the developed world, solid waste collection systems have become extremely important in relation to recycling and hygiene issues. Local governments have a responsibility to utilize the least costly and most sanitary types of such systems. However, when current practices are examined, it can be seen that, even in developed countries, waste collection is often carried out in an unhealthy and inefficient way, thus indicating the need for smart system solutions.

With the approach used, the smart waste collection system presented in this study applies technology that can solve the problems of the developed world efficiently, with the least cost and damage to the environment and in a way that is healthy, hygienic and fits in with modern city design. This system was developed by combining current technological advances and communications technology with knowledge gathered from years of experience in the field of solid waste collection.

System trials were carried out in an area with a population of 50,000, and the components of the system and the waste collection algorithm used in the project were optimized. According to the observations and surveys with the people, this proposed system was found to be satisfactory.

Although different approaches can be found in the literature, the one presented here is quite economical. At the end of the analyses, it was demonstrated that the proposed system would cost 50-80\% less than the existing system. After completion of the initial test setup of the system, it has been redesigned to be suitable for installation in larger cities.

Acknowledgments This project was supported by the 1501-TÜBITAK Industrial R\&D Project Support Program (Grant Number 3130224).

\section{References}

Abeliotis K, Karaiskou K et al (2009) Decision support systems in solid waste management: a case study at the national and local level in Greece. Glob NEST J 11(2):117-126

Arebey M, Hannan, MA et al (2010) RFID and integrated technologies for solid waste bin monitoring systems. In: Proceedings of the world congress on engineering 2010, vol I, WCE 2010, June 30-July 2, London, UK

Chen CC (2010) Spatial inequality in municipal solid waste disposal across regions in developing countries. Int J Environ Sci Technol 7(3):447-456

eBelediye. http://www.ebelediye.info/?pid=22721. Accessed 28 Jan 2014

European Environment Agency EAA Report No 2/2013. Managing municipal solid waste, a review of achievements in 32 European countries. ISSN 1725-9177, Copenhagen

Ezebilo EE, Animasaun ED (2011) Households' perceptions of private sector municipal solid waste management services: a binary choice analysis. Int J Environ Sci Technol 8(4):677-686

Faccio M, Persona A, Zanin G (2011) Waste collection multi objective model with real time traceability data. Waste Manag 31:2391-2405

Guerrero LA, Maas G, Hogland W (2013) Solid waste management challenges for cities in developing countries. Waste Manag 33:220-232

Hadjibiros K, Dermatas D, Laspidou CS (2011) Municipal solid waste management and landfill site selection in Greece: irrationality versus efficiency. Glob NEST J 13(2):150-161

Ismail Z, Loh SL (2009) Ant colony optimization for solving solid waste collection scheduling problems. J Math Stat 5(3):199-205

Johansson OM (2006) The effect of dynamic scheduling and routing in a solid waste management system. Waste Manag 26:875-885

Karadimas NV, Papatzelou K et al (2007) Optimal solid waste collection routes identified by the ant colony system algorithm. Waste Manag Res 25:139-147

Kop Y (2007) Fuzzy multi-criteria decision making in solid waste collection systems in Turkey. M.Sc. Thesis, Galatasaray University, Istanbul

Nuortio T, Kytojoki $\mathbf{J}$ et al (2006) Improved route planning and scheduling of waste collection and transport. Expert Syst Appl $30: 223-232$

Son LH (2014) Optimizing Municipal Solid Waste collection using Chaotic Particle Swarm Optimization in GIS based environments: a case study at Danang city, Vietnam. Expert Syst Appl 41(18):8062-8074

Vicentini F, Giusti A et al (2009) Sensorized waste collection container for content estimation and collection optimization. Waste Manag 29:1467-1472 
Viotti P, Polettini A et al (2003) Genetic algorithms as a promising tool for optimization of the MSW collection routes. Waste Manage Res 21:292-298
Zaman AU (2013) Identification of waste management development drivers and potential emerging waste treatment technologies. Int J Environ Sci Technol 10:455-464 